07,01

\title{
Соотношение Холла-Петча для размеров скачков деформации металлов
}

\author{
(C) В.В. Шпейзман, П.Н. Якушев
}

Физико-технический институт им. А.Ф. Иофрфе РАН,

Санкт-Петербург, Россия

E-mail: shpeizm.v@mail.ioffe.ru

Поступила в Редакцию 11 февраля 2019 г.

В окончательной редакции 11 февраля 2019 г.

Принята к публикации 12 февраля 2019 г.

\begin{abstract}
Предпринята попытка использовать соотношение Холла-Петча для описания связи предела текучести меди и титана в трех различных состояниях (исходном, отожженном и после равноканального углового прессования) с размерами нано- и микрометровых скачков деформации, измеренных с помощью прецизионной интерферометрической методики. Показано, что при деформации сжатием вблизи предела текучести можно наблюдать шесть уровней деформации с тремя нано- и тремя микрометровыми размерами скачков деформации от $1-2 \mathrm{~nm}$ до 20-35 $\mu \mathrm{m}$. Каждое из шести структурных состояний металлов характеризуется своим набором размеров скачков деформации. Построены зависимости пределов текучести меди и титана от размеров скачков $L^{-1 / 2}$ и обсуждены общие закономерности и особенности скачков деформации для каждого из металлов в различных структурных состояниях.
\end{abstract}

Ключевые слова: скачки деформации, предел текучести, соотношение Холла-Петча, уровни деформации.

DOI: 10.21883/FTT.2019.07.47841.377

\section{1. Введение}

Попытки связать макроскопические характеристики деформации (ее скорость, предел текучести и др.) с параметрами структуры материалов издавна были в центре внимания исследователей деформации. Одним из наиболее известных проявлений этой связи является соотношение Холла-Петча (ХП), которое выражает предел текучести $\sigma_{y}$ как линейную функцию $d^{-1 / 2}$, где $d$ - размер зерна материала. Исследуя температурную зависимость $\sigma_{y}$ для железа и мягкой стали с разным размером зерна, Холл и Петч, независимо друг от друга, установили, что $\sigma_{y}=\sigma_{0}+k d^{-1 / 2}[1,2]$. Впоследствии различными исследователями было показано, что формула ХП справедлива также и для других характеристик деформации и разрушения. Так, в [3-6] она была распространена на напряжения течения при одинаковой деформации на кривой растяжения $\sigma_{\varepsilon}$, на разрушающие напряжения $\sigma_{f}$, коэффициент интенсивности напряжений $K_{c}$ и вязкость разрушения $K_{1 c}$. Широкое применение соотношение ХП получило в исследованиях твердости и, особенно, микротвердости (см. например [7-9]). Используется эта зависимость также и при описании явления усталости, вязкохрупкого перехода и многих других деформационных процессов $[4,5]$. Подробное описание различных приложений соотношения ХП можно найти в обзоре [10], посвященном 60-летию его открытия.

Первоначальное объяснение зависимости ХП, которым часто пользуются до сих пор, связывает его с торможением плоского скопления дислокаций на границе зерна. Для преодоления его требуется создать кон- центрацию напряжений, которая определяется числом дислокаций в скоплении, ограниченным в свою очередь размером зерна. Эта модель часто подвергалась критике, поскольку больших скоплений дислокаций (pile-up) в зернах не наблюдалось экспериментально. Кроме того, она может быть использована для начальной стадии деформации, то есть вблизи предела текучести, но не годится для многочисленных приложений, перечисленных выше. Поэтому был предложен ряд других объяснений, в которых граница зерна различным образом активно участвует в деформации: путем генерирования дислокаций и образования „леса“ в приграничных областях [11], образования дислокаций несоответствия [12] или влиянием на величину свободного пробега внутризеренных дислокаций [13]. Теоретическое описание этих моделей дано в обзорах [14-16].

За верхнюю границу применимости формулы ХП $(d \gg)$, то есть величину $\sigma_{0}$, обычно принимают предел текучести монокристалла. Следует однако учитывать, что предел текучести, как и другие характеристики деформации и разрушения монокристаллов, зависят от ориентации. Интерес к нижней границе применимости формулы ХП в последнее время возрос в связи с многочисленными исследованиями свойств наноструктурных материалов, для которых наблюдались отклонения от формулы ХП. С уменьшением размера зерна коэффициент ХП $k$ уменьшается, а начиная с некоторого критического размера $d_{c r}$, изменяет знак, то есть предел текучести падает с уменьшением размера зерна. По разным данным первые отклонения начинаются с размеров $5 \cdot 10^{-2}-10^{2} \mu \mathrm{m}$, а вторые при 
$d<d_{c r} \approx 5-50 \mathrm{~nm}[16-20]$. Именно в этой области лежат размеры микро- и нанометровых скачков деформации, ${ }^{1}$ которые обнаружены в различных по своей природе материалах с использованием разработанной в ФТИ им. А.Ф. Иоффе интерферометрической методики измерения скорости и величины деформации [21-24]. Эта методика и новые программы обработки результатов позволили обнаружить и изучить разномасштабные повторяющиеся изменения скорости деформации, которые формируют микро- и нанометровые скачки осевой деформации при одноосном нагружении образца. В наших предыдущих исследованиях была установлена корреляция величины микрометровых скачков с размером зерна. При сравнении размеров скачков деформации ряда металлов в исходном состоянии и после равноканального углового прессования (РКУП) было показано, что они меньше у образцов после РКУП [22]. Размеры скачков деформации в монокристаллах LiF уменьшались с ростом содержания примесей, то есть с уменьшением свободного пробега дислокаций [22]. В последующие годы методика измерения размеров скачков деформации была существенно усовершенствована: увеличена деформационная база, на которой измерялась величина скачка (от единиц до десятков $\mu \mathrm{m}$ ), возросла частота измерений (от 0.1 до $1 \mathrm{kHz}$ ), появилась возможность анализировать нанометровые скачки. Все это привело к тому, что характерных для выбранных условий деформации размеров скачков оказалось $4-6$ : от $\sim 1 \mathrm{~nm}$ до $20-40 \mu \mathrm{m}$. В большинстве случаев более крупные скачки деформации состоят из скачков предыдущих уровней, хотя иногда встречаются одиночные скачки, не связанные со скачками деформации других уровней. По нашим представлениям, в процессе деформации постоянно формируются новые и разрушаются старые „границы“, которые препятствуют движению дислокаций. Размеры скачков деформации определяют ее уровень, а полный набор скачков отражает многоуровневый характер деформации. В настоящей работе предпринята попытка проверить зависимость типа ХП для размеров скачков деформации. С этой целью были изготовлены образцы меди и титана в трех различных состояниях: исходном, отожженном и после РКУП - и измерены скачки деформации в области напряжений, близких к пределу текучести.

\section{2. Образцы и методика исследования}

Опыты проводились на меди М1 $(99.98 \%)$ и $\alpha$-титане ВТ1-0 (99.55\%). В исходном состоянии средний раз-

\footnotetext{
${ }^{1}$ Следует отметить, что под „скачком деформации“ мы понимаем не только резкие, но и плавные изменения скорости деформации с последующим ее возвратом к значениям, близким к тем, которые были до скачка, если зависимость скорости деформации от времени слабая. Если эта зависимость сильная, то следует учитывать изменение среднего значения скорости за время скачка, то есть рассматривать отклонения текущего значения скорости деформации от ее значения на усредненной зависимости скорости от времени.
}

Таблица 1. Пределы текучести меди и титана с разным размером зерна

\begin{tabular}{c|c|c|c}
\hline Материал & $\begin{array}{c}\text { Структурное } \\
\text { состояние }\end{array}$ & $\begin{array}{c}\text { Размер зерна } \\
d, \mu \mathrm{m}\end{array}$ & $\begin{array}{c}\text { Предел текучести } \\
\sigma_{y}, \mathrm{MPa}\end{array}$ \\
\hline \multirow{4}{*}{ Медь } & после отжига & 100 & 150 \\
\cline { 2 - 4 } & исходное & 5 & 240 \\
\cline { 2 - 4 } & после РКУП & 0.2 & 320 \\
\hline \multirow{4}{*}{ Титан } & после отжига & 40 & 290 \\
\cline { 2 - 4 } & исходное & 2 & 403 \\
\cline { 2 - 4 } & после РКУП & 0.2 & 631
\end{tabular}

мер зерна в титане составлял 2 , в меди $-5 \mu \mathrm{m}$, в отожженном - соответственно 40 и $100 \mu \mathrm{m}$, после РКУП $-200 \mathrm{~nm}$ в обоих материалах. Измеренные нами пределы текучести при сжатии указанных материалов представлены в табл. 1.

Образцы имели форму цилиндра с диаметром $d=3$ и высотой $l_{0}=6 \mathrm{~mm}$. Нагружение сжатием с постоянной осевой нагрузкой производилось на установке, в которой скорость деформации определялась с помощью лазерного интерферометра. Напряжение подбиралось таким образом, чтобы в начале опыта средняя скорость деформации была $(2-4) \cdot 10^{-5}$, а в конце $-(1-5) \cdot 10^{-6} \mathrm{~s}^{-1}$, что позволяло достичь изменения длины образца $\Delta l \sim 50 \mu \mathrm{m}$, достаточного для анализа скачков скорости и величины деформации. Схема и возможности интерферометра и нагружающего устройства изложены в [21-23]. По частоте биений на интерферограмме определяли скорость, а по числу биений - величину деформации. Частота дискретизации при записи интерферограмм составляла $1 \mathrm{kHz}$. Средняя скорость деформации при изменении длины образца $\Delta l_{0}=325 \mathrm{~nm}\left(\Delta l_{0}=\lambda / 2\right.$, где $\lambda-$ длина волны лазера, используемого в установке, $\lambda=650 \mathrm{~nm}$ ) определялась по формуле $\dot{\varepsilon}=\Delta l_{0} /\left(l_{0} \Delta t\right)$, где $\Delta t-$ период биения на интерферограмме. Это означает, что в рассматриваемом интервале скоростей деформации каждое биение содержало от нескольких тысяч до десятков тысяч точек, что позволяло надежно определять период и контролировать форму биений. Специально разработанная программа позволяла обрабатывать большие массивы экспериментальных данных [23]. Величину скачка деформации $L$ в микрометровом диапазоне рассчитывали по зависимости скорости относительной деформации $\dot{\varepsilon}$ от изменения длины образца $\Delta l$ как расстояние между близкими по величине скачками скорости деформации. При этом выпадают из рассмотрения крайне редкие гигантские скачки скорости деформации, один из которых показан на рис. $1, a, b$. На фрагменте интерферограммы длительностью $\sim 100 \mathrm{~s}$ расположены 8 биений и вертикальная линия при $t \approx 1200 \mathrm{~s}$. Однако если рассмотреть это 
Таблица 2. Микрометровые скачки деформации $L, \mu \mathrm{m}$

\begin{tabular}{c|c|c|c|c|c|c}
\hline \multirow{2}{*}{ № } & \multicolumn{3}{|c|}{ Титан } & \multicolumn{3}{c}{ Медь } \\
\cline { 2 - 7 } & после отжига & исходный & после РКУП & после отжига & исходный & после РКУП \\
\hline 1 & $1.95 \pm 0.78$ & $1.76 \pm 0.42$ & $1.10 \pm 0.39$ & $1.13 \pm 0.42$ & $0.92 \pm 0.31$ & $0.89 \pm 0.27$ \\
2 & $15.2 \pm 1.0$ & $10.0 \pm 2.0$ & $8.6 \pm 2.3$ & $5.3 \pm 0.9$ & $3.5 \pm 2.0$ & $2.83 \pm 0.76$ \\
3 & & 34 & & $20.6 \pm 11.6$ & $14.9 \pm 4.1$ & 8.9
\end{tabular}

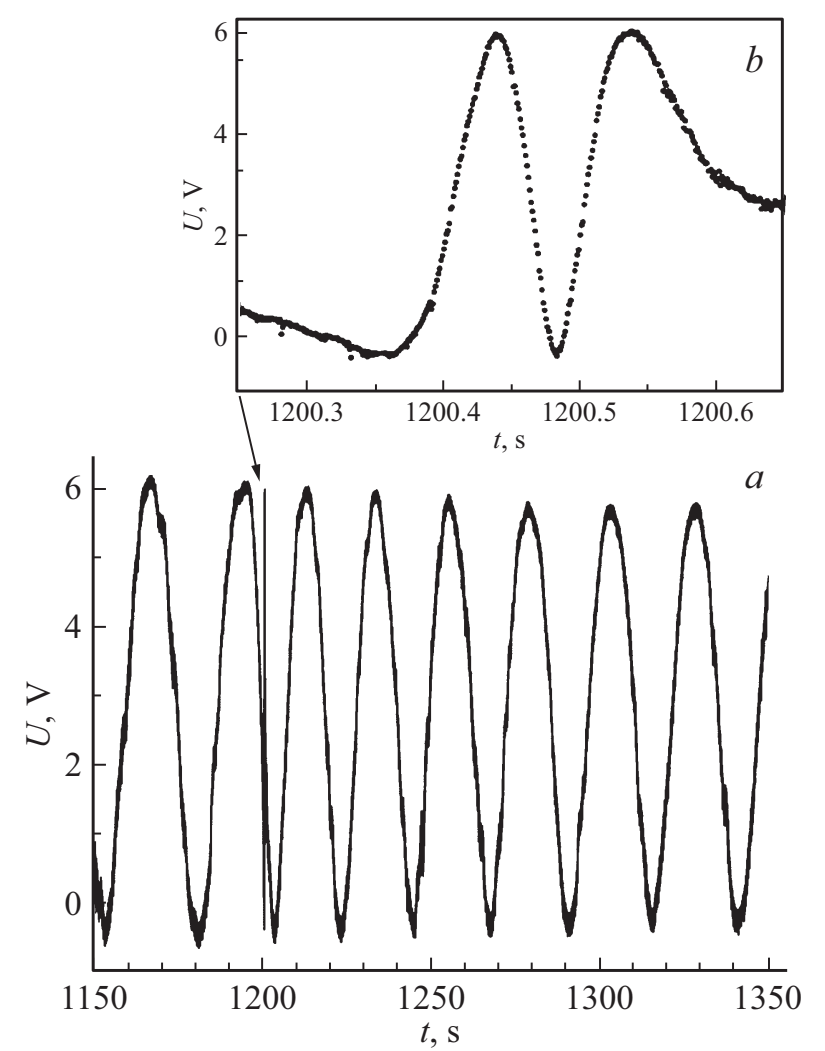

Рис. 1. Пример изменения скорости на коротком отрезке деформации в $\sim 200$ раз. Рис. $1, a$ и $b$ различаются масштабом оси времени. Стрелкой указано место, откуда взят рис. $1, b$.

место интерферограммы детально (рис. $1, b$ ), то можно увидеть биение высокой частоты, соответствующее скорости деформации $5 \cdot 10^{-4} \mathrm{~s}^{-1}$, в то время как до и после этого биения скорость деформации была соответственно 2 и $3 \cdot 10^{-6} \mathrm{~s}^{-1}$. Заметим, что несмотря на короткое время скачка скорости деформации $(\sim 0.1 \mathrm{~s})$, он привел к заметному ускорению деформации даже на фоне убывания со временем ее средней величины.

Интервал изменения высоты скачка $L$ ограничен с одной стороны расстоянием между точками измерения скорости, а с другой - полной величиной рассматриваемого участка кривой деформации. В соответствии с задачей настоящей работы этот интервал составлял от $0.7-1 \mu \mathrm{m}$ (2-3 измерения скорости в скачке) до 30-40 $\mathrm{m}$ (1-2 скачка в полной деформации образца).
Нанометровые скачки, меньшие $325 \mathrm{~nm}$, определялись по отклонению формы биений на интерферограмме от расчетной, согласно которой величина сигнала $U=U_{0} \cos (\Delta \omega t)$, где частота биений $\Delta \omega$ представляет собой разность частот исходного и отраженного от образца лучей лазера. Поскольку $\Delta t=2 \pi / \Delta \omega$, то $\dot{\varepsilon}=\lambda \Delta \omega / 4 \pi l_{0}$. За меру отклонений экспериментальной кривой биений $U(t)$ от расчетной принималась разность ординат $\Delta U$ зависимостей $U(t)$ и аппроксимированной $\cos (\Delta \omega t)$, нормированной на амплитуду биения $U_{0}$. Таким образом можно было определить скачки деформации от $\sim 1$ до десятков $\mathrm{nm}$. В некоторых случаях удавалось построить аппроксимированную кривую для ряда последовательных биений и обнаружить скачки размером 100 и более $\mathrm{nm}$ и приблизиться к области микрометровых скачков.

\section{3. Результаты и обсуждение}

На рис. 2, $a-f$ приведены экспериментальные точки и усредненные кривые зависимости скорости деформации от времени для Ті и $\mathrm{Cu}$ в различных структурных состояниях. Среднеквадратичное отклонение для точек приведенных кривых различаются несильно: для титана оно изменяется от 0.06 до 0.08 , для меди - от 0.05 до 0.09 (случайные гигантские скачки наблюдались не во всех случаях и в расчетах во внимание не принимались). Каких-либо закономерностей в изменении среднеквадратичного отклонения скорости в связи со структурой материала обнаружено не было.

На врезках на рис. 2, $a-f$ показаны относительные отклонения скорости $\Delta \dot{\varepsilon} / \dot{\varepsilon}$ от ее значений на усредненной кривой в зависимости от накопленной деформации $\Delta l$, по которым определялась величина $L$. Средние значения и среднеквадратичные отклонения величины микрометровых скачков деформации приведены в табл. 2. Все скачки деформации в выбранной области измерений можно условно разбить на три группы. Самые малые микрометровые скачки для всех структурных состояний меди, а также для титана после РКУП находились в пределах от $0.65 \mu \mathrm{m}$ (2 биения на интерферограмме) до $1.7 \mu \mathrm{m}$, а для исходного и отожженного титана от 1.3 до $3 \mu \mathrm{m}$. Для средних значений величины скачка деформации наблюдается следующая закономерность: чем мельче зерно, тем меньше средняя величина скачка деформации. То же соотношение справедливо для более 

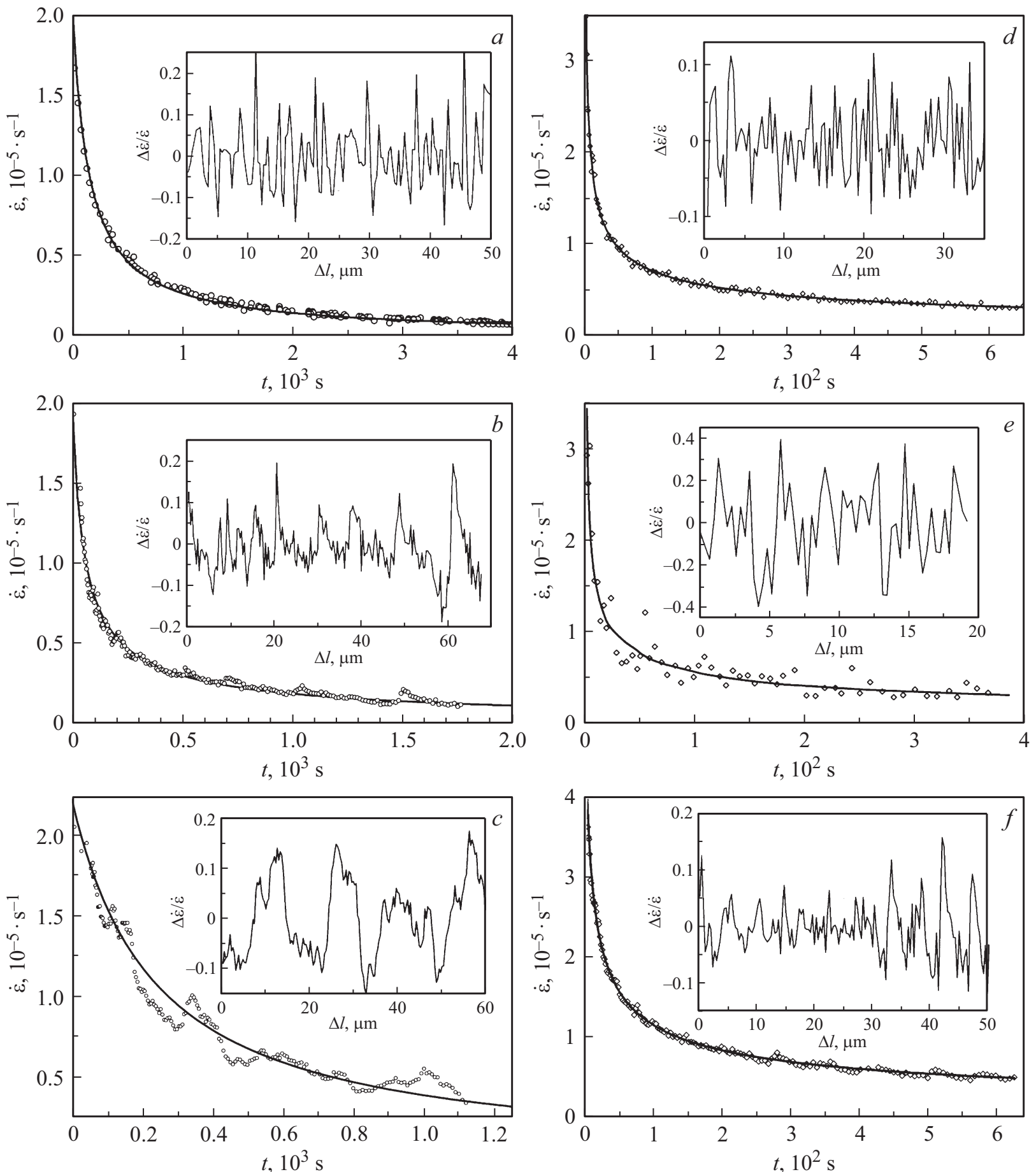

Рис. 2. Экспериментальная зависимость скорости деформации от времени (точки) и усредненная кривая. На врезках относительное отклонение скорости деформации от усредненной кривой в зависимости от деформации; $a, b, c-$ титан, $d, e, f-$ медь; $a, d-$ материал в исходном состоянии, $b, e-$ после РКУП, $c, f-$ после отжига.

крупных скачков с размерами от 1.5 до $7 \mu \mathrm{m}$ в меди и от 5 до $18 \mu \mathrm{m}$ в титане. В обоих случаях для одинаковых структурных состояний скачки деформации в титане крупнее, чем в меди. Что касается самых больших из измеренных скачков, то на кривых деформации титана встречались одиночные скачки размером не более $30-40 \mu \mathrm{m}$. Это ограничение связано с быст- рым падением скорости деформации и, как следствие, небольшой общей деформацией образца при постоянных напряжениях, близких к пределу текучести. Однако для меди, где средние размеры больших микрометровых скачков оказались также меньше, чем в титане, можно заметить, что тенденция увеличения размера скачка с ростом размера зерна сохраняется и для них. 

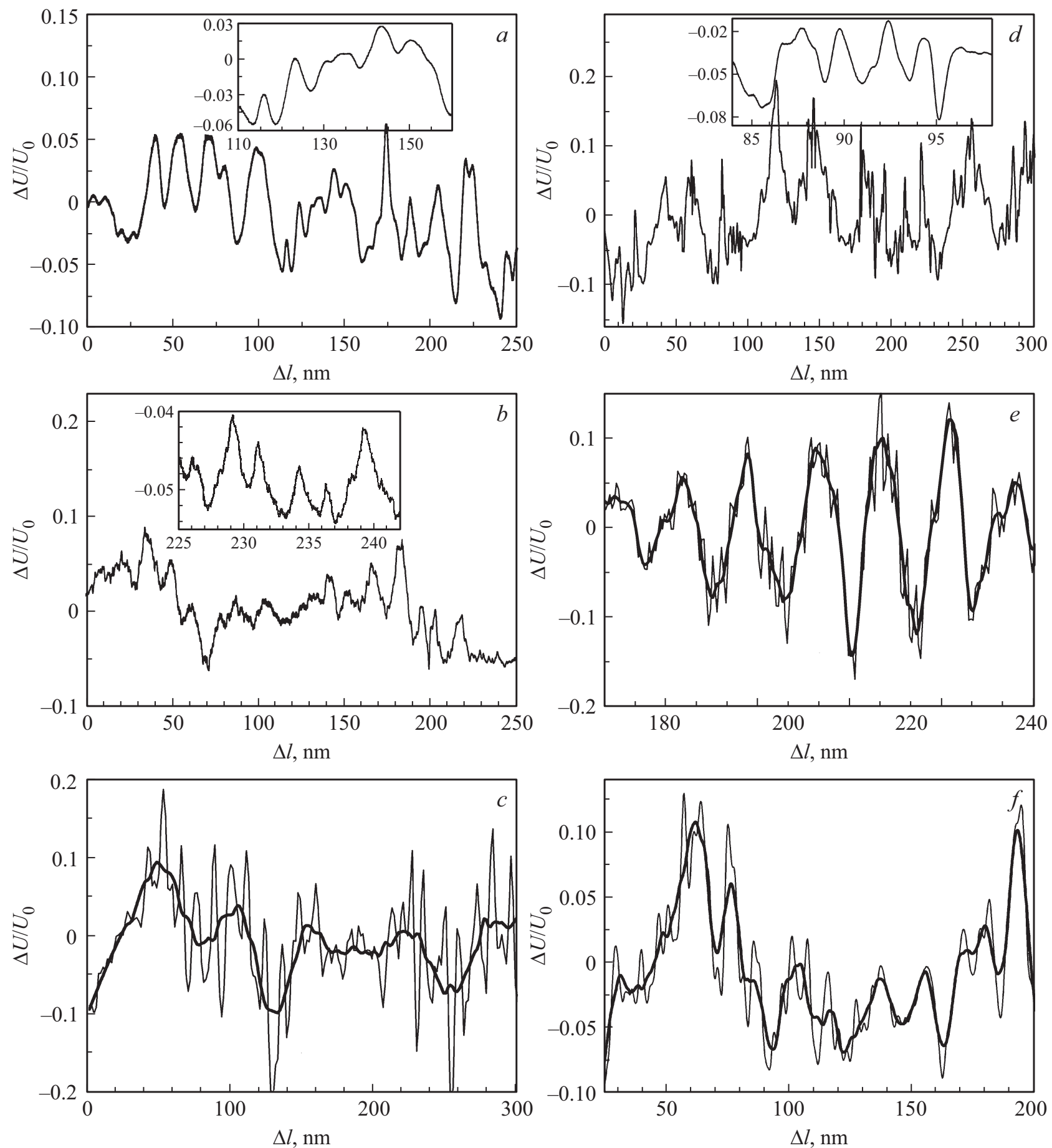

Рис. 3. Нанометровые скачки деформации; $a, b, c-$ титан, $d, e, f-$ медь; $a, d-$ материал в исходном состоянии, $b, e-$ после РКУП, $c, f-$ после отжига. На врезках - участки кривых в более крупном масштабе.

Нанометровые скачки деформации, измеренные в пределах одного биения на интерферограмме, показаны на рис. 3, $a-f$. По аналогии с микрометровыми скачками деформации, размер скачка определялся как расстояние между близкими по величине пиками зависимости $\Delta U / U_{0}(\Delta l)$. На рис. $3, c, e, f$ видно, что группы мелких скачков образуют более крупный скачок. На остальных рисунках для того, чтобы показать наличие скачков двух размеров, на врезки выведены участки кривых основного графика в более крупном масштабе. Как и для микрометровых скачков деформации, среднеквадратичные отклонения от близких к нулю средних значений для точек кривых на рис. $3, a-f$ различаются несильно и составляют 0.4-0.6. В табл. 3 приведены средние значения и среднеквадратичные отклонения величины нанометровых скачков деформации, рассчитанные по тому же 
Таблица 3. Нанометровые скачки деформации $L, \mathrm{~nm}$

\begin{tabular}{c|c|c|c|c|r|r}
\hline \multirow{2}{*}{ № } & \multicolumn{3}{|c|}{ Титан } & \multicolumn{3}{c}{ Медь } \\
\cline { 2 - 7 } & после отжига & исходный & после РКУП & после отжига & \multicolumn{1}{|c}{ исходный } & после РКУП \\
\hline 4 & $12.2 \pm 1.6$ & $6.8 \pm 1.5$ & $2.6 \pm 0.7$ & $6.9 \pm 2.40$ & $2.2 \pm 0.6$ & $1.5 \pm 0.5$ \\
5 & $61.0 \pm 12.9$ & $24.1 \pm 10.3$ & $12.4 \pm 3.7$ & $20.5 \pm 5.2$ & $19.2 \pm 8.9$ & $10.9 \pm 1.0$ \\
6 & & 250 & $180 \pm 9$ & & & 150
\end{tabular}

принципу, что и аналогичные величины для микрометровых скачков. В выбранных биениях наблюдались по три группы скачков для каждого материала в различных структурных состояниях: малые скачки до 10 в меди и $15 \mathrm{~nm}$ в титане, средние - до 30 в меди и $75 \mathrm{~nm}$ в титане, а также крупные скачки величиной более $100 \mathrm{~nm}$. Скачки больших размеров трудно было обнаружить, анализируя только одно биение $\left(\Delta l_{0}=325 \mathrm{~nm}\right)$. Поэтому была предпринята попытка рассмотреть несколько последовательных биений с очень близкими частотами, что давало возможность приблизиться по размерам к микрометровым скачкам. Единичные большие скачки были найдены для наноструктурной меди ( 150 nm) и для исходного и мелкозернистого титана (соответственно $\sim 250$ и $180 \mathrm{~nm})$. Как видно из приведенных данных, сделанные выводы для микрометровых скачков о росте их величины с увеличением размера зерна и при переходе от меди к титану справедливы и для нанометровых скачков.

На рис. 4, $a, b$ построены зависимости предела текучести меди и титана от размера скачков в координатах ХП: $\sigma_{y}-L^{-1 / 2}$. Там же приведена аналогичная зависимость для размера зерна. Зависимость $\sigma_{y}-d^{-1 / 2}$ для титана хорошо описывается прямой с $\sigma_{0}=(275 \pm 16) \mathrm{MPa} \mathrm{и} k=(0.16 \pm 0.01) \mathrm{MPa} / \mathrm{m}^{1 / 2}$. Для меди экспериментальные точки не лежат на прямой; если все же попытаться построить ее с помощью метода наименьших квадратов, то получим большой разброс коэффициентов уравнения ХП $\left(\sigma_{0}=(173 \pm 39) \mathrm{MPa}\right.$ и $\left.k=(0.07 \pm 0.03) \mathrm{MPa} / \mathrm{m}^{1 / 2}\right)$, а $\sigma_{0}$ выше предела текучести отожженной меди. Следует заметить, что отклонение от линейности зависимости ХП в микрометровой области для меди наблюдались ранее [19].

Как видно из рис. $4, a, b$, для исходного и мелкозернистого материала одна из точек зависимостей $\sigma_{y}-L^{-1 / 2}$ близка к одной из точек зависимости $\sigma_{y}-d^{-1 / 2}$, то есть всегда есть скачки деформации, близкие к размеру зерна, что отмечалось нами ранее [22]. Очень крупные скачки, близкие к размеру зерна отожженного материала мы не могли наблюдать из-за малой общей деформации образца. Для исходных и после РКУП материалов оказалось, что скачки, близкие к размеру зерна, принадлежат разным семействам. Так, для материала со средней величиной зерна этими скачками являются микрометровые скачки, малые для титана и средние для меди, а для мелкозернистого - самые большие нанометровые скачки для обоих металлов.
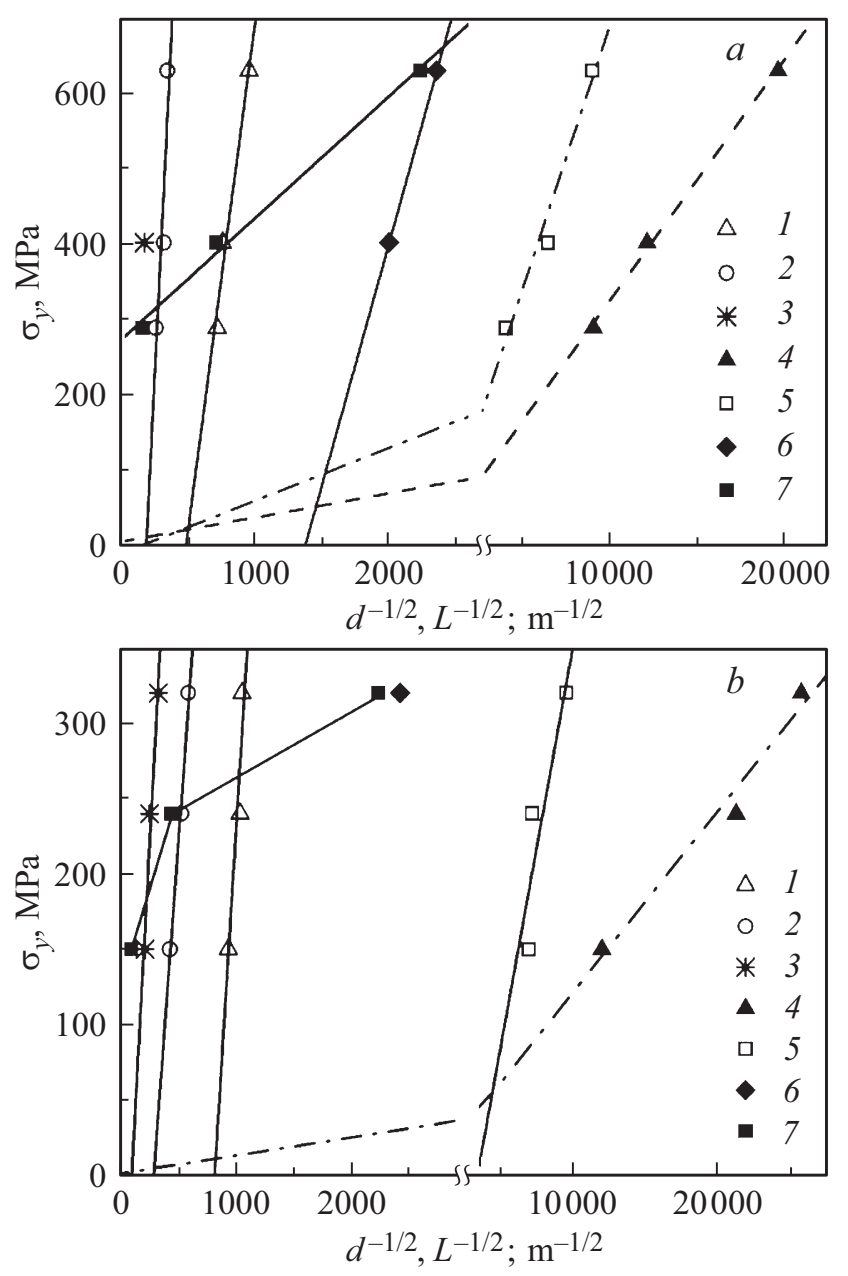

Рис. 4. Соотношение Холла-Петча для размеров скачков деформации $(a)$ титана и $(b)$ меди. Номера точек $1-6$, по которым построены прямые, соответствуют номерам строк в табл. 2, 3; (7) - зависимость Холла-Петча для размера зерна.

Полученные результаты показывают, что для меди и титана, исходных и после РКУП, имеются скачки деформации, в несколько раз превышающие размер зерна. Для металлов после РКУП это относится ко всем микрометровым скачкам деформации, а для исходной меди к крупным и исходного титана к средним и крупным микрометровым скачкам. Если полагать, что размеры скачков деформации соответствуют неким характерным размерам областей, в которых происходит самосогла- 
сованное движение групп дислокаций, приводящее к деформации, то большие скачки должны включать в себя не только внутризеренные процессы, но и процессы, захватывающие границы зерен. Большие скачки состоят из скачков меньшего размера, в которых происходят аналогичные согласованные перемещения и так далее до самых малых скачков.

Зависимости $\sigma_{y}-L^{-1 / 2}$ для всех типов скачков можно описать линейными функциями, но ход их для микрои нанометровых скачков сильно различается. ${ }^{2}$ Для всех типов скачков их размер растет с ростом размера зерна. Разница в величине скачков деформации, принадлежащих одной группе, в меди и в титане может быть связана с корреляцией размера скачков с величиной вектора Бюргерса металлов [24]: у титана 0.286 nm против 0.255 у меди. В координатах ХП наклон функций $\sigma_{y}-L^{-1 / 2}$ для микрометровых скачков больше, чем для функции $\sigma_{y}-d^{-1 / 2}$, а для нанометровых скачков меньше. Исключение составляют большие нанометровые скачки деформации в меди, для которых наклон зависимости $\sigma_{y}-L^{-1 / 2}$ близок к наклону прямой $\sigma_{y}-d^{-1 / 2}$, если последнюю описывать одной прямой.

При анализе рис. $4, a, b$ и данных таблиц 2,3 следует учитывать, что приведены средние значения размеров скачков. Если же построить распределения размеров скачков, то они плавно переходят из одного семейства в другое во всех случаях, кроме участка межу микрои нанометровыми скачками. Причиной этого является отсутствие надежной методики определения размеров больших нанометровых скачков.

Очевидно, что параметрам зависимостей $\sigma_{y}-L^{-1 / 2}$ нельзя приписывать такой же смысл, как в соотношении ХП, поскольку в противном случае параметр $\sigma_{0}$ был бы отрицательным или нулевым. Любопытно, что близкое к нулю значение $\sigma_{0}$ для размеров некоторых видов нанометровых скачков приводит к постоянству произведения $\sigma_{y} L^{1 / 2}$ или $\sigma_{y}^{2} L / E$, где $E-$ модуль упругости, то есть позволяет, по аналогии с преобразованием коэффициента интенсивности напряжений $K_{1}$ в $J-$ интеграл в теории распространения трещины, рассматривать эту постоянную как энергетическую характеристику деформации, связанную со скачком данного вида.

\section{4. Заключение}

Скачки деформации различной природы известны давно и им посвящено большое число исследований. Развиваемые нами представления об общности скачков деформации и возможности характеризации уровня деформации по величине скачка позволяют конкретизировать понятие уровня в описании деформации как многоуровневого процесса. В [22-24] и ряде других наших работ были измерены скачки деформации кристаллических тел, полимеров и композитов и показано

\footnotetext{
${ }^{2}$ На прямых, проведенных пунктиром, излом связан с изменением масштаба оси $X$, а не с изменением вида функции $\sigma_{y}-L^{-1 / 2}$.
}

влияние на величину скачков разнообразных способов воздействия на твердые тела, приводящие к изменению их структуры. В настоящей работе впервые изучена возможность количественного описания связи величины скачков с известными характеристиками деформации. Было выбрано, пожалуй, наиболее известное выражение - соотношение Холла-Петча, удобное еще и тем, что при его трансформации, описанной выше, не меняется размерность входящих в него величин. Полученное подтверждение правильности выражения ХП при замене входящего в него размера зерна на размеры микрои нанометровых скачков деформации вселяет надежду на то, что развитие работ в этом направлении будет полезным для лучшего понимания природы скачков деформации и самого процесса деформации твердых тел.

\section{Конфликт интересов}

Авторы заявляют, что у них нет конфликта интересов.

\section{Список литературы}

[1] E.O. Hall. Proc. Phys. Soc. B 64, 747 (1951).

[2] N.J. Petch. J. Iron Steel Inst. 174, 25 (1953).

[3] N. J. Petch. Phil. Mag. 1, 186 (1956).

[4] R.W. Armstrong, I. Codd, R.M. Douthwaite, N.J. Petch. Phil. Mag. 7, 45 (1962).

[5] T. Yokobori, A.T. Yokobori,Jr., K. Sato, M. Omotani. Eng. Fract. Mech. 17, 75 (1983).

[6] N.J. Petch, R.W. Armstrong. Acta Met. 37, 2279 (1989).

[7] A.S. Taha, F.H. Hammad. Phys. Status Solidi A 119, 455 (1990).

[8] R.W. Armstrong, W.L. Elban. Mater. Sci. Technol. 28, 1060 (2012).

[9] R.W. Armstrong. Met. Trans. 1, 1169 (1970).

[10] R.W. Armstrong. Mater. Trans. 55, 2 (2014).

[11] J.C.M. Li. Trans. Met. Soc. AIME 277, 239 (1963).

[12] M.F. Ashby. Phil. Mag. 21, 399 (1970).

[13] H. Conrad. Acta Met. 11, 75 (1963).

[14] Г.А. Малыгин. ФТТ 49, 961 (2007).

[15] M. Kato. Mater. Trans. 55, 19 (2014).

[16] М.Ю. Гуткин, И.А. Овидько. Успехи механики 2, 68 (2003).

[17] Р.3. Валиев, А.К. Емалетдинов, О.А. Кайбышев. ФММ 54, 604 (1982).

[18] G. Palumbo, U. Erb, K.T. Aust. Scripta Met. Mater. 24, 2347 (1990).

[19] E.V. Kozlov, A.N. Zhdanov, N.A. Popova, E.E. Pekarskaya. Mater. Sci. Eng. A 387, 1, 789 (2004).

[20] A.M. Glezer, E.V. Kozlov, N.A. Koneva, N.A. Popova, I.A. Kurzina. Plastic Deformation of Nanostructured Materials. CRC Press. (2017), 334 p.

[21] Н.Н. Песчанская, П.Н. Якушев. ФТТ 30, 2196 (1988).

[22] Н.Н. Песчанская, Б.И. Смирнов, В.В. Шпейзман. ФТТ 50, 815 (2008).

[23] В.В. Шпейзман, П.Н. Якушев, В.М. Егоров, С.В. Васильева, А.С. Смолянский. ФТТ, 2018 60, 1341 (2018).

[24] В.В. Шпейзман. ПЖТФ 44, 15, 80 (2018).

Редактор Т.Н. Василевская 